\title{
Mapeamento dos países nas Cadeias Globais de Valor: uma análise dos fluxos de comércio e de renda de propriedade intelectual
}

Mapping countries in Global Value Chains: an analysis of trade and Intellectual property income flows

\begin{abstract}
This article aims at mapping the countries participation in Global Value Chains (CGV) simultaneously to the behavior of trade flows and income for the use of intellectual property, in a pioneering empirical approach in the literature regarding value chains involving technological variables. For this, it were analyzed the countries participation in value chains and the pattern of variation of trade flows and income for the use of intellectual property. The mapping was done with 41 countries between 1995 and 2011, using five indicators that captured characteristics inherent to participation in this process. Given the amount of information, clusters analysis was used, identifying that the countries which increased their participation in global chains generally presented worsening in intellectual property income account usually accompanied by improvement in trade account. The result obtained with the methodology converges with the recent discussion of greater participation of the developing countries in CGV to be accompanied by greater external technological dependence.
\end{abstract}

\section{Keywords}

Global Value Chains, upgrading, intellectual property, cluster analysis.

JEL Codes F23, L23, O14, O34.

\author{
Ludmila Macedo Corrêa (1) \\ Eduardo Costa Pinto (2) \\ Marta dos Reis Castilho(3) \\ (1) Universidade Federal Rural do Rio de Janeiro \\ (2) Universidade Federal do Rio de Janeiro \\ (3) Universidade Federal do Rio de Janeiro
}

\section{Resumo}

Este artigo visa mapear a participação dos países nas Cadeias Globais de Valor (CGV) simultaneamente ao comportamento dos fluxos comerciais e de renda de pagamento pelo uso de propriedade intelectual numa abordagem empírica pioneira na literatura referente às cadeias de valor envolvendo variáveis tecnológicas. Para isso, analisaram-se a participação dos países nas cadeias e o padrão das variações dos saldos comerciais e de renda de pagamento pelo uso de propriedade intelectual. O mapeamento foi feito com 41 países entre 1995 e 2011, utilizando cinco indicadores que captaram características inerentes à participação nesse processo. Diante da quantidade de informação, utilizou-se análise de clusters, identificando-se que os países que mais aumentaram sua participação nas cadeias apresentaram geralmente piora na conta de renda de pagamento pelo uso de propriedade intelectual, frequentemente acompanhada por melhora na balança comercial. O resultado obtido com a metodologia converge para a discussão recente de maior participação dos países em desenvolvimento nas CGVs ser acompanhada de maior dependência tecnológica externa.

\section{Palavras-chave}

Cadeias Globais de Valor, upgrading, propriedade intelectual, análise de cluster.

Códigos JEL F23, L23, O14, O34. 


\section{Introdução}

A fragmentação internacional da produção e formação das Cadeias Globais de Valor (CGV) expandiu-se significantemente nas últimas décadas, modificando o perfil mundial da produção e do comércio. Esse novo formato de organização da produção permitiu ampla gama de possibilidades de inserção dos países nas cadeias globais com diferentes resultados sobre suas economias. A participação nas cadeias contribui geralmente para o crescimento do produto e exportações dos países envolvidos e, para alguns, proporciona também mudanças mais expressivas como maior sofisticação da composição de suas estruturas produtivas.

Essas mudanças na composição do comércio e da estrutura produtiva desses países estão gerando impactos relevantes sobre os fluxos de renda de pagamento pelo uso de propriedade intelectual. Os países em desenvolvimento que se inserem nas CGVs sofisticam-se tecnologicamente utilizando tecnologia ou conhecimento mais avançados desenvolvidos no exterior, sendo estes altamente protegidos por direitos de propriedade intelectual. Com isso, esses países vão, por um lado, apresentar geralmente variações positivas nos saldos comerciais decorrentes de sua maior inserção e, por outro, remeter fluxos crescentes de renda de pagamento pelo uso de propriedade intelectual em função da proteção da tecnologia ou da marca utilizada, acentuando ainda mais seus déficits recorrentes na balança de serviço.

Diante desses efeitos, este artigo tem como objetivo mapeara participação dos países nas CGVs - com base em estatísticas de comércio - simultaneamente ao comportamento de seus fluxos comerciais e de renda de pagamento pelo uso de propriedade intelectual numa abordagem empírica pioneira na literatura referente às CGVs envolvendo variáveis tecnológicas, cujo assunto é analisado geralmente no âmbito do comércio. Recentemente, identificou-se o surgimento de trabalhos teóricos tratando a questão tecnológica, mais especificamente a criação de ativos intangíveis, sem fazer, entretanto, nenhuma análise empírica a respeito.

Diante dessa lacuna e visando verificar se os dados empíricos estão compatíveis com essas discussões iniciais, o mapeamento foi feito com uma amostra de 41 países no período entre 1995 e 2011, utilizando cinco indicadores que captam características inerentes à participação dos países nas CGVs. Dada a quantidade de informação, optou-se por utilizar a técnica de clusters, que permite uma análise conjunta de indicadores para 
mapear o comportamento dos países na cadeia, de forma a identificar padrões de participação dos países nas cadeias e o comportamento dos fluxos comerciais e de renda de pagamento pelo uso de propriedade intelectual.

\section{Participação dos países nas CGVs e o comporta- mento dos fluxos comerciais e de renda de pagamen- to pelo uso de propriedade intelectual}

Esta seção visa apresentar as características gerais das CGVs e os tipos de inserções dos países, em especial os países em desenvolvimento, e também discutir como esse tipo de inserção pode provocar mudanças nos fluxos comerciais dos países e, sobretudo, nos fluxos de pagamentos de renda pelo uso de propriedade intelectual.

\subsection{Cadeias globais de valor: padrões de atuação e ganhos decor- rentes}

A fragmentação internacional da produção e a formação das CGVs expandiram-se acentuadamente, a partir dos anos de 1990, como estratégia de internacionalização das grandes corporações, que identificaram nesse modelo organizacional um mecanismo para aumentar eficiência produtiva e rentabilidade num cenário de maior concorrência diante a liberalização e desregulamentação dos mercados.

O fatiamento e distribuição da cadeia de processos produtivos descontínuos em diferentes regiões imprimiram novas características à divisão internacional do trabalho, resultando um reposicionamento da produção e do comércio no entorno de redes globais/regionais, e reconfigurando os países em desenvolvimento no cenário internacional (Sarti \& Hiratuka, 2010; Baldwin, 2012; Milberg \&Winkler, 2013, Corrêa et al., 2019).

Com a fragmentação do processo produtivo, a localização das etapas nas diferentes regiões condiciona-se às vantagens comparativas de cada etapa do processo produtivo (Memedovic \& Iapadre, 2009). Essa mudança se deve ao fato de as diferentes etapas gerarem diferentes níveis de agregação de valor, e quando separadas existe a possibilidade de os países concentrarem-se na captura de valor adicionado (VA) em etapas especí- 
ficas. Aquelas com maior VA são etapas pré e pós-fabricação, formadas principalmente por serviços - concepção, design, $\mathrm{P} \& \mathrm{D}$, marketing e serviços pós-venda - cujos potenciais de criação de VA das atividades são descritos na smile curve (Baldwin, 2012).

Diante dos diferenciais de captura de VA entre as atividades da cadeia produtiva, identificam-se os países em desenvolvimento atuando geralmente como fornecedores de matérias-primas ou em processamento e montagem de produto final, enquanto os países desenvolvidos, uma crescente participação na produção de peças e componentes de alta tecnologia ou em segmentos de serviços, como atividades de criação do produto, atividades estas de maior criação de VA (Memedovic \& Iapadre, 2009). Em algumas situações, observa-se a distribuição geográfica de algumas atividades sofisticadas que, embora se concentrem nos países desenvolvidos, os países em desenvolvimento vêm conquistando espaços maiores nessas atividades. Tal inserção não ocorre homogeneamente, com o desempenho desse grupo fortemente associado ao desenvolvimento de competências tecnológicas em determinadas áreas de conhecimento, permitindo-nos captar investimentos estrangeiros em atividades mais nobres (Miranda, 2014).

Essa recente reconfiguração espacial das etapas de produção entre países decorre dos novos modelos de governança das firmas que fazem parte das CGVs, cujo modelo é determinado por suas posições hierárquicas nas cadeias, que influenciam a extensão da captura do VA de cada uma dessas firmas (Sturgeon \& Gereffi, 2009).

Fundamentada nessa lógica, Pinto et al. (2015) e Corrêa et al. (2019) identificam a existência de dois tipos de agentes: as firmas líderes (sediadas principalmente nos países desenvolvidos) e que são detentoras do controle sobre tecnologia, $\mathrm{P} \& \mathrm{D}$, propriedade intelectual e marcas, capturando com isso a maior parte do VA; e as empresas contratadas pelas firmas líderes (presentes nos países em desenvolvimento) e que realizam frequentemente etapas manufatureiras de baixo VA e serviços pouco intensivos em conhecimento, ou quando presentes, totalmente protegidos por direitos de propriedade.

Em termos gerais, afirma-se que a "descentralização da cadeia de produção ocorre de forma hierárquica e seletiva” (Sarti \& Hiratuka, 2010). Hierárquica pelo fato de a maior parcela do VA do processo produtivo continuar geralmente na matriz dessas grandes corporações (firmas líderes) com a terceirização ocorrendo somente nas atividades de baixo VA. E é seletiva, devido à hierarquização na distribuição do valor adicionado tam- 
bém ocorrer entre os países. As etapas terceirizadas, pelo fato de serem em geral intensivas em trabalho ou recursos naturais, são transferidas via firmas contratadas para países em desenvolvimento, abundantes nesses fatores. Ressalta-se ainda que a internacionalização das atividades tecnológicas preserva o caráter hierárquico e seletivo similar à esfera produtiva. As firmas líderes controlam a distribuição das atividades, indo somente para países que apresentarem vantagem tecnológica ou de conhecimento para desenvolvê-las (Miranda, 2014).

A descentralização geográfica das cadeias ocorre paralelamente ao maior controle das grandes corporações em relação ao restante das firmas envolvidas no que se refere à natureza dos contratos e à transferência de tecnologia, refletindo no aumento da concentração do poder de comando sobre a criação de valor adicionado. Milberg e Winkler (2013) defendem ainda que a preservação da captura assimétrica de VA entre os agentes envolvidos é endógena às estratégias das corporações, evidenciando resistência a qualquer alteração de posição dos países em desenvolvimento na atuação nessas cadeias.

Pelo lado das empresas contratadas, identifica-se que a atração de etapas produtivas intensivas em mão de obra dos países centrais contribui para a obtenção de ganhos como geração de emprego, renda e aumento das exportações, possibilitando, também, a sofisticação da composição dessas exportações. Anteriormente, esses países caracterizavam-se por serem exportadores de produtos primários, mas com a fragmentação internacional da produção, suas pautas exportadoras passaram a apresentar peso significativo de manufaturas intensivas em tecnologia e/ou maior expressividade de serviços sofisticados.

Diante disso, observa-se que a participação nessas redes internacionais de produção representa para muitos países um avanço na industrialização implicando, no curto prazo, crescimento das exportações, emprego e renda (Memedovic \& Iapadre, 2009; UNCTAD, 2013). Em alguns desses países, identificam-se ainda os ganhos estendendo-se para o longo prazo, com atuação crescente em segmentos industriais sofisticados ou em atividades intensivas em conhecimento, gerando efeitos de transbordamento para outros setores (UNIDO, 2013).

Para aqueles que se restringiram aos ganhos de curto prazo, a mudança do padrão de especialização da economia influenciado pela inserção nas cadeias pode restringir-se ao setor exportador, com efeitos de encadea- 
mento sobre a economia limitados. Nesse caso, a sofisticação da pauta exportadora não significa melhora da estrutura produtiva do país, podendo configurar o aprisionamento em atividades de baixo VA.

Assim, constata-se que as diferentes potencialidades de ganhos obtidos com as CGVs relacionam-se à etapa de atuação na cadeia produtiva e ao efeito de transbordamento dessa atividade sobre a economia (via encadeamento e potencial de learning da atividade). Esses transbordamentos incentivam uma atuação mais sofisticada, seja em termos de cadeias, seja em atividades intensivas em conhecimento, afetando positivamente a composição de sua estrutura produtiva e do nível de produtividade, e configurando um ganho de longo prazo.

A atuação dos países nas cadeias podem ser a mesma desde o momento da inserção ou então sofisticar-se ao longo do tempo via upgrading. Para alguns, a participação limita-se à atividade desempenhada na inserção, enquanto para outros, observa-se uma participação estendida, com avanços referentes à: maior eficiência de seus processos produtivos (upgrading de processo); ou melhores produtos produzidos (upgrading de produto); ou direcionamento para cadeias de valor mais sofisticadas (upgrading de cadeia); e/ou atividade desempenhada em termos de intensidade de conhecimento (upgrading funcional). Os diferentes padrões de atuação nas cadeias (inserção e upgrading) implicam também diferentes resultados (Milberg \& Winkler, 2013; UNCTAD, 2013, Humphrey \& Schmitz, 2002).

Com upgrading de produto e/ou processo, a posição do país nas cadeias é fortalecida, e com o apoio da firma líder (dado o maior retorno para elas) têm-se ganhos de curto prazo em termos de exportação e produto, sem, entretanto ser suficiente para a modificação de sua estrutura produtiva. Já no upgrading de cadeia e/ou funcional, os ganhos da atuação são potencializados em função do efeito de transbordamento de cadeias ou atividades mais sofisticadas, podendo, nesse caso, impactar positivamente na composição de suas estruturas de produção. $O$ padrão de atuação (principalmente o upgrading funcional), embora seja desestimulado pelas empresas líderes devido ao receio de perder espaço na captura de VA nas cadeias, beneficia os países que o realizam graças ao potencial de sustentar os ganhos ao longo do tempo (Milberg \& Winkler, 2013).

Como destacado anteriormente, os distintos potenciais de ganhos da participação nas CGVs associam-se ao conteúdo tecnológico ou de conhecimento dessa atuação, seja setorial ou de atividade desenvolvida. 
E quando não houver os aspectos citados, destacou-se a possibilidade de evolução nesse padrão de atuação via upgrading de cadeia ou funcional, contornando, com isso, o aprisionamento em setores ou atividades de baixo potencial de criação de VA.

Entretanto, ressalta-se que a evolução não é automática. A simples participação não garante ao país obter os ganhos inerentes a essa evolução. Identifica-se desinteresse das firmas líderes ou mesmo imposição de dificuldades para os países em desenvolvimento avançarem no padrão de atuação. Assim, são necessários esforços específicos em termos de política econômica voltados para o processo de endogenização tecnológica, cuja discussão foge do escopo do presente artigo (Sturgeon \& Memedovic, 2010, Ernest \& Kim, 2002).

\subsection{Cadeias Globais de Valor e rendas de pagamento pelo uso de propriedade intelectual}

A propagação e difusão das CGVs vieram acompanhadas da defesa e imposição de um sistema internacional de propriedade intelectual pelos países desenvolvidos, destacadamente o papel assumido pelos Estados Unidos no âmbito da Organização Mundial do Comércio (OMC). Isso ocorre via exigência de um padrão mínimo de proteção intelectual aos países membros da organização, que devem abdicar ou adequar seus sistemas nacionais ao padrão internacional determinado pelo Trade Related Intelectual Property System (TRIPS) (Pinto et al., 2015; Durand \& Milberg, 2018). Com isso, as empresas transnacionais - sediadas geralmente nos países desenvolvidos e que lideram o processo de fragmentação internacional da produção - asseguram o controle de marcas, segredos industriais, conhecimento e, simultaneamente, a terceirização de etapas produtivas e o consequente "empréstimo de tecnologia". Este consiste em disponibilizar especificamente a tecnologia e/ou conhecimento utilizados na atividade, altamente protegidos e sem possibilidade de decodificação e enraizamento local (Baldwin, 2012).

Além da apropriação dos royalties de patentes e marcas, esse sistema de propriedade intelectual assegura o poder de comando das empresas que possuem posições dominantes nas cadeias, determinando a distribuição da captura de VA entre os participantes. Nesse caso, o sistema garante o 
padrão de governança na cadeia, impedindo ou dificultando o upgrading dos países em desenvolvimento nessas cadeias, caso isso represente perda de captura de VA pelas empresas líderes (Pinto et al., 2015). A garantia da propriedade intelectual assegura o poder de monopólio dessas firmas (monopólio intelectual), cujo poder decorre da criação de ativos intangíveis (Pagano's, 2014; Aguiar de Medeiros \& Trebat, 2017). Assim, a atuação das corporações nesse paradigma produtivo - e a internacionalização da tecnologia - contribui não para uma convergência tecnológica, mas para consolidar as assimetrias entre os países (Miranda, 2014).

Numa linha similar, Carlotto e Pinto (2015) defendem o estabelecimento de um padrão internacional de propriedade intelectual que beneficia diretamente interesses comerciais americanos e que acentua a atual divisão internacional do trabalho e a assimetria tecnológica entre os países desenvolvidos e em desenvolvimento. A "diplomacia da propriedade intelectual" decorrente da imposição de um padrão internacional de propriedade intelectual garante o controle científico e tecnológico compensando também os déficits comerciais dos EUA, processo este acentuado pela transferência de etapas produtivas manufatureiras para outros países.

Assim, na discussão sobre paradigma produtivo inerente às CGVs e a consolidação de um sistema internacional de propriedade intelectual, identificam-se efeitos microeconômicos, mas que transbordam para a esfera macroeconômica.

O primeiro refere-se ao controle e comando de determinados agentes econômicos (empresas líderes) sobre o conhecimento/tecnologia, proporcionando-lhes maior captura de VA, em oposição à maior subordinação dos agentes responsáveis por atividades não sofisticadas. Sobre os efeitos macroeconômicos, como o primeiro grupo encontra-se geralmente nos países desenvolvidos, e o segundo nos países em desenvolvimento, isso dificultará a estes últimos avançar nas cadeias sob a forma de upgrading, obtendo de forma limitada os efeitos de longo prazo dessa atuação. A performance obtida em cada um dos grupos refletirá na composição da conta corrente de seus balanços de pagamentos. Os participantes de etapas produtivas finais de montagem recebem o "título" de exportadores de bens finais e, com isso, afetam positivamente os saldos comerciais, enquanto os atuantes em etapas sofisticadas de criação e desenvolvimento de produtos (ativos intangíveis) representam os exportadores de conhecimento, tecnologia e marca, com impacto positivo sobre suas balanças de serviço. 
Nesse sentido, constatam-se a difusão das CGVs e o avanço de alguns países em desenvolvimento em seus processos de industrialização a partir da participação nesse paradigma produtivo. No entanto, a superficialidade dessa industrialização (Baldwin, 2012) limita o aprofundamento desse processo devido à ampliação da dependência de tecnologia e conhecimento oriundos dos países desenvolvidos. Esse cenário pode refletir nos saldos negativos nos fluxos de renda de pagamento pelo uso de propriedade intelectual, e que acentuam os déficits recorrentes nas balanças de serviços, podendo não ser compensados totalmente por balanças comerciais superavitárias decorrentes da exportação de produtos manufaturados.

Diante da propagação das CGVs e da crescente participação dos países em desenvolvimento nessas cadeias, identifica-se como importante mapear o padrão dessa atuação simultaneamente ao comportamento dos fluxos comerciais e de renda de pagamento pelo uso de propriedade intelectual. A seguir, a descrição e a justificativa dos indicadores selecionados nesse mapeamento.

\section{Indicadores para o mapeamento: descrição e justifi- cativas}

A análise da participação dos países nas CGVs é feita frequentemente por estudos de casos de países/setoriais ou então por análise agregada dos países, entretanto baseada em algum indicador específico, geralmente relacionado a comércio (UNCTAD, 2013; 2018; Banga, 2013; De Backer \& Mirodout, 2013). Sobre o primeiro método, Milberg \& Winkler (2013) destacam sua limitação decorrente da dificuldade de comparabilidade dos resultados. O segundo, por sua vez, embora permita a comparação do desempenho dos países em uma variável específica, é limitado por não captar simultaneamente os efeitos das cadeias em diferentes dimensões econômicas, cujas variáveis em conjunto podem expressar determinados padrões de comportamento nas CGVs.

Diante dessas limitações metodológicas e da lacuna existente nas análises empíricas das CGVs referentes à dimensão tecnológica, optou-se por um mapeamento dos países nas cadeias baseado numa análise multivariada, considerando-se indicadores que captem a intensidade da participação e também indiquem a sofisticação dessa atuação, em paralelo a 
indicadores que analisem o comportamento dos fluxos comerciais simultaneamente aos fluxos de pagamento pelo uso de propriedade intelectual. Os indicadores baseiam-se em estatísticas de comércio em termos de VA e estatísticas de comércio e serviços do balanço de pagamento.

\subsection{Estatísticas de comércio em termos de valor adicionado}

As estatísticas de comércio podem ser mensuradas em termos de VA estimando-se a origem do valor (país e indústria) adicionado na produção voltada para a exportação. Ao fazer a distinção entre VA doméstico e importado, analisa-se a importância do comércio internacional na criação de valor local e de criação de emprego. Essa distinção num cenário de fragmentação internacional da produção é fundamental diante da utilização elevada de insumos importados na produção de bens finais. A estatística de comércio em termos de VA é calculada a partir de uma matriz insumo-produto global oriunda da harmonização de matrizes insumo-produto dos países e dos coeficientes de comércio bilaterais (OECD-WTO, 2012).

Para melhor compreensão, considere-se que as exportações brutas dos países (X) são formadas pelo valor adicionado doméstico (DVA) e pelo valor adicionado estrangeiro (FVA). No DVA, identifica-se uma parcela utilizada na demanda doméstica de outros países (DVAxDF) e outra incorporada nas exportações desses outros países (DVAx*). A análise do comércio nas cadeias de valor baseia-se somente no VA dos países incorporado nas exportações de terceiros (DVAx*).

Assim, a participação de um país nas CGVs é mensurada considerando-se sua participação a jusante (DVAx*), como criador de valor adicionado embutido nas exportações de outros países, e sua participação a montante (FVA), utilizando-se VA importado nas suas exportações (Koopman et al., 2008). O índice de participação nas cadeias ao ser expresso em relação às exportações mostra a contribuição das exportações intracadeia nas exportações totais do país. Como primeiro e segundo indicadores para o mapeamento dos países nas CGVs, serão utilizados, respectivamente, o Índice de Participação (IP) de um país nas CGVs em 2011 e a sua variação entre 1995 e 2011:

$$
\text { Indicador 1: } I P=\left[\left(D V A x^{*}+F V A\right) / X\right]
$$


onde: $\Delta$ refere-se à variação; $I P$, ao Índice de Participação; $D V A x *$, ao VA doméstico contido nas exportações de terceiros; FVA, ao VA estrangeiro contido nas exportações nacionais e; $X$, às exportações brutas.

$O$ índice de participação, embora amplamente utilizado na literatura sobre as CGVs, apresenta limitações. O VA doméstico criado pelos países que atuam na etapa de montagem/processamento de bens finais (exportadores de bens finais) é voltado à demanda doméstica de outros países e, com isso, ignorado pelo IP. Nesse caso, terão a participação nas cadeias contabilizada apenas via VA estrangeiro (FVA), fato que explica o baixo IP de alguns países conhecidos como altamente integrados às cadeias.

Outra questão de destaque sobre o indicador refere-se à preponderância da importância do componente a jusante "DVAx" sobre o "FVA" por ser o que agrega valor localmente. Participação elevada nas cadeias decorrente de elevada importação de VA estrangeiro pode gerar problemas para o país, como se caracterizarem por meros "juntadores de peças" com baixa agregação de valor local. Nessa linha de priorizar o VA doméstico, Banga (2013) ressalta a importância do componente voltado para a demanda final de outros países "DVAxDF", mesmo para aqueles com grande participação nas cadeias.

Diante disso, optou-se por avaliar a variação do VA doméstico das exportações (DVA), cujo indicador é utilizado por diversos autores como proxy de upgrading econômico (Milberg \& Winkler, 2013; Taglioni \& Winkler, 2016; Banga, 2014; Smichowski et al., 2018). Avalia-se, com isso, a capacidade de criação de VA local das exportações, seja decorrente de exportações intracadeia, seja voltada para a demanda doméstica de outros países, sendo que estas últimas podem ser decorrentes de transbordamentos da primeira. Assim, será adotada como terceiro indicador para o mapeamento dos países nas CGVs a variação do VA doméstico nas exportações entre 1995 e 2011:

Indicador 3: $\triangle$ Participação do VA doméstico nas exportações $=\Delta(D V A / X)$

onde: $\Delta$ refere-se à variação; $D V A$, ao VA doméstico nas exportações e; $X$, às exportações brutas. 
A fragmentação produtiva e a deslocalização geográfica das diferentes etapas envolveram também serviços, com muitas dessas atividades sendo executadas em terceiros países. Identifica-se no processo produtivo de bens uma série de serviços utilizados (transporte, TI, financeiros...) que agregam valor ao produto. Ao distinguir o valor adicionado de cada uma dessas atividades, vê-se exatamente o que cada setor está produzindo. Diante da maior capacidade de criação de VA de alguns serviços e das estatísticas de comércio em termos de VA identificar a contribuição de cada setor nas exportações brutas, optou-se por estender a análise aos serviços. Visa-se identificar se a maior participação nas cadeias foi acompanhada de maior participação de serviços intensivos em conhecimento e com maior capacidade de geração de VA nas exportações, representando uma sofisticação da atuação desses países nas cadeias.

Assim, com base na desagregação setorial da base de dados TIVA, utilizou-se como quarto indicador a variação do VA doméstico dos serviços: "financeiros"; "aluguel de maquinarias" e "serviços de negócios". Estes últimos abrangem "computação e atividades relacionadas" e "P\&D e outras atividades de negócios relacionadas".

Indicador 4:

$\triangle$ Participação do VA doméstico em serviços sofisticados nas exportações = $\Delta(D V A s A, B, C / X)$

onde: $\Delta$ refere-se à variação; $D V A S A, B, C$, ao valor adicionado doméstico em serviços $A, B$, e $C$ contido nas exportações, sendo: a) serviços financeiros; b) aluguel de maquinarias; c) serviços de negócios e; $X$, exportações brutas.

Para o cálculo dos indicadores desta seção, utilizou-se a base OECD-WTO Trade in Value-Added (TIVA) - maio 2015, com informações em termos de VA para 62 economias em 33 setores (classificação STAN. rev.3).

\subsection{Estatísticas do balanço de pagamento: balança comercial e de renda de pagamento pelo uso de propriedade intelectual}

Anteriormente, discutiu-se o estabelecimento de um sistema de propriedade intelectual internacional como elemento importante na propagação das CGVs pelo fato de ele garantir o poder de comando das empresas lí- 
deres na distribuição da captura de VA entre os países participantes. Além disso, a detenção desses direitos de propriedade tem garantido aos países desenvolvidos fluxos de renda na forma de royalties decorrentes de uso de licenças de tecnologia/produtos pelos países em desenvolvimento e, em contrapartida, maior dependência destes via aumento das despesas com pagamento pelo uso de propriedade intelectual (Pinto et al., 2015; Aguiar de Medeiros \&Trebat, 2017; Durand \& Milberg, 2018; Carlotto \& Pinto, 2015).

Esses artigos em conjunto sugerem que o padrão de atuação dos países nas CGVs reflete na composição da conta corrente do balanço de pagamento, com alterações da balança comercial e da balança de serviços, especificamente a subconta de renda de pagamento pelo uso de propriedade intelectual. Neste caso, a variação das contas ocorre geralmente em direção contrária.

Diante dessas discussões e da ausência de análises empíricas dessas variáveis no âmbito das CGVs, são calculadas para os países da amostra entre 1995 e 2011: a) variação do saldo do pagamento pelo uso de propriedade intelectual ${ }^{1}$ (PIntelec) e; b) variação do saldo da balança comercial (BC). Busca-se identificar os padrões entre a variação desses saldos nos diferentes países de forma a verificar empiricamente a ideia defendida por esses autores de relação inversa entre esses saldos.

$\Delta$ Saldo do pagamento pelo uso de propriedade intelectual $=$ $\Delta[$ crédito de PIntelec - débito de PIntelec]

$$
\Delta \text { Saldo da Balança Comercial }=\Delta[\text { crédito da } B C-\text { débito da } B C]
$$

Para esses cálculos são utilizados os dados de BP da base de dados do Fundo Monetário Internacional (FMI). Ressalta-se que em função da maior volatilidade dos fluxos da balança de serviços, o cálculo da variação dos saldos no período é feito com base na diferença entre a média dos três anos finais e iniciais.

Visando identificar padrões entre os saldos, criou-se uma categorização dos quatro padrões existentes possíveis entre os países, expressos na Tabela 1. Números negativos na categorização referem-se à relação 1 Os pagamentos pelo uso de propriedade intelectual englobam: licença de exploração de patentes, fornecimento de tecnologia, assistência técnica, uso de marcas e software,... 
inversa entre as variações, enquanto números positivos, à variação na mesma direção. Nos extremos, 2 e -2, identificam-se padrões de variação negativo do saldo do pagamento pelo uso de propriedade intelectual, enquanto 1 e -1 , variação positivo do saldo do pagamento pelo uso de propriedade intelectual.

Tabela 1 Categorização dos padrões da variação dos saldos de renda de propriedade intelectual e da balança comercial

\begin{tabular}{rrrr}
\hline$\Delta$ Saldo PIntelec & $\Delta$ Saldo BC & Categorização \\
\hline- & - & 2 \\
\hline+ & + & 1 \\
\hline+ & - & -1 \\
\hline- & + & -2 \\
\hline
\end{tabular}

Fonte: Elaboração própria.

O padrão "-2" refere-se aos países com aumento da dependência de uso de propriedade intelectual externa simultaneamente a uma balança comercial mais superavitária. Já no padrão "2", além da maior dependência de conhecimento/tecnologia externos, houve também aumento da importação líquida de bens.

O padrão "-1" refere-se aos países que aumentaram as exportações líquidas de conhecimento/tecnologia e as importações líquidas na BC. E o padrão "1",aqueles com maiores superávits em ambas as contas.

Assim, o quinto indicador no mapeamento dos países nas CGVs refere-se aos quatro padrões existentes entre variação dos saldos do pagamento pelo uso de propriedade intelectual e da balança comercial discriminados nos números da categorização. ${ }^{2}$

Indicador 5: Padrões da variação dos saldos de Pagamento pelo uso de

Propriedade Intelectual (PIntelec) e da Balança Comercial (BC)

Os indicadores foram calculados para 41países, escolhidos com base na disponibilidade de dados (TIVA-OCDE e FMI) e em algumas característi-

2 Visando-se identificar indicador mais preciso que expressasse relação entre essas variáveis, calculou-se a razão da variação dos dois saldos, interpretando o indicador como a importância da "PIntelec" em relação a "BC". Embora esse indicador consiga distinguir se os saldos variam na mesma direção ou não, ele não discerne o sentido das direções de cada um, fazendo-nos optar pela categorização. 
cas dos países. Exceto o indicador 1, os indicadores são de variação, permitindo identificar a evolução dos países nos aspectos ressaltados. ${ }^{3}$

\section{Descrição dos resultados: análise conjunta dos indi- cadores}

A análise isolada dos indicadores evidenciou alguns aspectos referentes às CGVs. A primeira refere-se ao índice de participação dos países nas cadeias. Os países com maior IP em 2011 são economias pequenas dependentes de insumos importados, com demanda externa atuando como mercado consumidor importante para a sua produção, e geralmente atuando em posições intermediárias nas cadeias (Corrêa, 2016; 2019; Banga, 2013; UNCTAD, 2013; ...). A Tabela 2 ilustra essas informações.

No que se refere à importância do setor de serviços em termos de criação de VA, percebe-se na Tabela 2 que, entre os países que mais cresceram nas cadeias, poucos o fizeram via serviços sofisticados (DVAs A,B,C). A correlação negativa significativa entre essas variáveis (IP e DVAs A,B,C) confirma isso. ${ }^{4}$ Esse resultado mostra que os países que mais aumentaram o volume de comércio intracadeia não desenvolvem geralmente atividades de serviços intensivas em conhecimento.

Outro aspecto observado refere-se ao VA doméstico das exportações. Com o indicador, identificou-se que os países que apresentaram maior crescimento do IP nas cadeias foram os que mais perderam DVA, conforme Tabela 2. A acentuada relação inversa entre esses indicadores é confirmada pela elevada correlação negativa, a mais alta entre os indicadores. Com base na literatura que considera o DVA como proxy de upgrading econômico, esse resultado converge para as discussões acerca dos obstáculos ao upgrading funcional e, com isso, limitação da participação nas cadeias como mecanismo de aumentar a criação de VA local e também dos possíveis transbordamentos para a economia.

Sobre o indicador 5, o resultado mostra os países apresentando geralmente relação contrária entre variação do saldo do pagamento pelo uso de

3 Os dados dos indicadores calculados para a amostra encontram-se no Apêndice.

4 A matriz de correlação calculada através do software estatístico SPSS encontra-se no Apêndice. 
propriedade intelectual e variação do saldo da balança comercial. ${ }^{5} \mathrm{~A}$ alta correlação negativa dessas variáveis confirma isso. Esse resultado converge para a ideia defendida em Carlotto e Pinto (2015) e Pinto et al. (2015) de maiores déficits comerciais dos países desenvolvidos acompanhados por maiores superávits na subconta renda de pagamentos pelo uso de propriedade intelectual, e os países em desenvolvimento apresentando geralmente resultado em direção contrária. Assim, observa-se entre os países em desenvolvimento da amostra, exceto México e Hungria, melhora dos saldos comerciais simultaneamente a maior dependência tecnológica via renda de pagamento de propriedade intelectual.

Tabela 2 Relações entre indicadores selecionados

\begin{tabular}{l|r|r|r|r}
\hline & 1) & 2) & 3) & $\mathbf{4}$ \\
\cline { 2 - 5 } & $\mathbf{I P}$ & $\Delta \mathbf{P}$ & $\Delta \mathbf{D V A}$ & $\Delta$ DVAs A,B, \\
\cline { 2 - 6 } & $\mathbf{2 0 1 1}$ & $\mathbf{1 9 9 5 - 2 0 1 1}$ & $\mathbf{1 9 9 5 - 2 0 1 1}$ & $\mathbf{1 9 9 5 - 2 0 1 1}$ \\
\hline Coreia & 0,62 & 0,23 & $-0,19$ & 0,02 \\
\hline Hungria & 0,65 & 0,22 & $-0,19$ & $-0,01$ \\
\hline İndia & 0,43 & 0,20 & $-0,15$ & 0,06 \\
\hline Polônia & 0,56 & 0,20 & $-0,16$ & 0,02 \\
\hline Turquia & 0,41 & 0,19 & $-0,17$ & $-0,01$ \\
\hline Tailândia & 0,54 & 0,18 & $-0,15$ & 0,00 \\
\hline Japão & 0,47 & 0,18 & $-0,09$ & 0,00 \\
\hline Camboja & 0,49 & 0,18 & $-0,24$ & 0,01 \\
\hline$\ldots .$. & & & & \\
\hline EUA & 0,40 & 0,09 & $-0,04$ & 0,06 \\
\hline Suécia & 0,54 & 0,09 & $-0,03$ & 0,05 \\
\hline México & 0,47 & 0,08 & $-0,04$ & $-0,01$ \\
\hline Filipinas & 0,51 & 0,08 & 0,06 & 0,00 \\
\hline Irlanda & 0,59 & 0,08 & $-0,05$ & 0,14 \\
\hline Canadá & 0,42 & 0,07 & 0,01 & 0,02 \\
\hline Cingapura & 0,62 & 0,07 & 0,01 & 0,06 \\
\hline Holanda & 0,48 & 0,06 & 0,03 & 0,11 \\
\hline Hong Kong & 0,44 & 0,06 & 0,01 & 0,06 \\
\hline China & 0,48 & 0,05 & 0,01 & 0,01 \\
\hline Fon & & & &
\end{tabular}

Fonte: Elaboração própria.

5 Dados disponíveis no Apêndice, inclusive as variações dos saldos que geraram a categorização. 
Apesar de os indicadores isolados evidenciarem tendências referentes às CGVs, optou-se para o mapeamento, por uma análise conjunta desses indicadores considerando-se simultaneamente os aspectos ressaltados por eles. Assim, para identificar padrões entre os países da amostra em relação à participação nas cadeias e o comportamento dos fluxos comerciais e de renda de propriedade intelectual foi utilizada a técnica de agrupamento ou clusters ${ }^{6}$. A escolha metodológica se justifica pela adequação da utilização de análises exploratórias de dados quando não houver modelo teórico ou então hipóteses iniciais (Kubrusly apud Kupfer e Hasenclever, 2002; Johnson \& Wichern, 2007). Ressalta-se que, embora a metodologia não expresse relação de causalidade entre as variáveis, o mapeamento contribui para verificar empiricamente se os dados convergem com as discussões iniciais referentes à maior dependência tecnológica dos países em desenvolvimento via participação nas CGVs.

Os clusters foram calculados para 41 países e cinco indicadores, utilizando-se diferentes técnicas aglomerativas. Diante da inexistência de um padrão entre as técnicas, e considerando-se o objetivo do trabalho de analisar a participação dos países nas CGVs e o padrão de variação dos fluxos comerciais e de pagamento pelo uso de propriedade intelectual, adotou-se o cluster selecionando-se apenas os indicadores de índice de participação (indicadores 1 e 2). ${ }^{7}$

O resultado mostrou três grupos com padrões claros referentes à intensidade de participação nas cadeias, e com algumas outras características se manifestando entre eles. São eles:

a) países com niveis mais baixos de participação nas CGVs;

b) países com grande crescimento de participação nas CGVs e relevância média do comércio intracadeia nas exportações totais;

c) países com grande crescimento de participação nas CGVs e relevância significativa do comércio intracadeia nas exportações totais.

6 A técnica de agrupamento baseia-se na criação de grupos para os elementos da amostra com características similares, reunidos por meio de medidas de distância que definirão as (dis)similaridades entre esses elementos. Quando não se souber a priori o número de grupos a serem criados, estes serão formados hierarquicamente, com os elementos reunindo-se a cada etapa, respeitando alguma técnica aglomerativa. Assim, os grupos criados são cada vez maiores, mas em menor quantidade, sendo a quantidade escolhida baseada nas características priorizadas (Johnson \& Wichern, 2007).

7 Clusters calculados através do software estatístico SPSS via agrupamento hierárquico, com distância entre os elementos ficando elevada (maior heterogeneidade entre eles) com resultados abaixo de três grupos. Alguns países foram deslocados dos grupos originais, de forma a clarear determinados padrões entre as variáveis. 
A Tabela 3 resume a composição dos grupos e as respectivas características em termos de indicadores que os distinguem uns dos outros.

Tabela 3 Mapeamento dos países nas CGVs segundo intensidade de participação

\begin{tabular}{|c|c|c|c|}
\hline & Grupo 1 & Grupo 2 & Grupo 3 \\
\hline & $\begin{array}{r}\text { África do Sul } \\
\text { Alemanha } \\
\text { Argentina } \\
\text { Austrália } \\
\text { Áustria } \\
\text { Brasil } \\
\text { Canadá } \\
\text { China } \\
\text { Colômbia } \\
\text { Costa Rica } \\
\text { Espanha } \\
\text { Estados Unidos } \\
\text { Filipinas } \\
\text { França } \\
\text { Holanda } \\
\text { Hong Kong } \\
\text { Indonésia } \\
\text { Israel } \\
\text { Itália } \\
\text { México } \\
\text { Portugal } \\
\text { Reino Unido } \\
\text { Rússia } \\
\text { Suíça } \\
\text { Suécia }\end{array}$ & $\begin{array}{r}\text { Camboja } \\
\text { Chile } \\
\text { Índia } \\
\text { Polônia } \\
\text { Tailândia } \\
\text { Turquia } \\
\text { Japão }\end{array}$ & $\begin{array}{r}\text { Cingapura } \\
\text { Coreia } \\
\text { Eslováquia } \\
\text { Eslovênia } \\
\text { Irlanda } \\
\text { Malásia } \\
\text { Rep. Checa } \\
\text { Bulgária } \\
\text { Hungria }\end{array}$ \\
\hline \multicolumn{4}{|l|}{ Indicadores } \\
\hline 1) IP2011 & $\begin{array}{r}\text { Baixo } \\
(<50 \%)\end{array}$ & $\begin{array}{r}\text { Médio } \\
(\sim 50 \%)\end{array}$ & $\begin{array}{r}\text { Alto } \\
(\sim 62 \%)\end{array}$ \\
\hline 2) $\Delta I P$ & Baixa ou Média & $\begin{array}{r}\text { Alta } \\
(>>0)\end{array}$ & $\begin{array}{l}\text { Média ou Alta } \\
(>0 \text { ou }>>0)\end{array}$ \\
\hline 3) $\triangle \mathrm{DVA}$ & $(>0$ ou $<0)$ & $(<<0)^{1}$ & $(<<0 \text { ou }<0)^{2}$ \\
\hline 4) $\triangle \mathrm{DVAs} A, \mathrm{~B}, \mathrm{C}$ & ---- & ---- & ---- \\
\hline 5) PIntelec_BC & ---- & $\begin{array}{r}(--)^{3} \\
(-+)\end{array}$ & $(-+)^{4}$ \\
\hline
\end{tabular}

Fonte: Elaboração própria.

Legenda: $\Delta$ (variação); IP (índice de participação); DVA (VA doméstico nas exportações); DVAs A,B,C (VA de serviços sofisticados nasexportações); > ou < (variação média); $>>$ ou $<<$ (variação alta). 
Notas: ${ }^{1}$ Chile e Japão: $\triangle D V A(<0) ;{ }^{2}$ Cingapura: $\triangle D V A(>0) ;{ }^{3}$ Japão: PIntelec_BC (+-); ${ }^{4}$ Bulgária: PIntelec_BC (--) e Hungria: PIntelec_BC (++).

Além disso, utilizou-se (----) quando não se identificou padrão do indicador entre os países do mesmo grupo. As notas de rodapé na tabela referem-se às exceções. No Apêndice, encontram-se os dados detalhados dos países, organizados de acordo com os grupos gerados pela técnica de cluster.

Vejamos os grupos detalhadamente.

\section{Grupo 1 Países com níveis mais baixos de participação nas cadeias}

O grupo 1 é formado por países com níveis de participação nas cadeias mais baixos, em termos de variação e também em 2011. Por ser um grupo grande, apresenta disparidades nas outras variáveis, demandando a criação de subgrupos que permitam identificar padrões referentes às outras características. Destaca-se, ainda, que entre esses países o DVA sofreu pouca redução no período, ou mesmo pequenos aumentos.

Diante da heterogeneidade entre esses países e a ausência de padrão entre eles (exceto baixo IP), adotou-se novamente o cluster, priorizando o indicador de propriedade intelectual.

A Tabela 4 mostra os grupos gerados com base no indicador 5 . As colunas e linhas distinguem, respectivamente, a direção da variação dos saldos de renda de propriedade intelectual e da variação dos saldos da BC. As últimas duas linhas da tabela distinguem os indicadores "DVA" e "DVAs $\mathrm{A}, \mathrm{B}, \mathrm{C}$ ".

O resultado inesperado refere-se ao México, cujo indicador mostrou padrão típico de país desenvolvido, variação positiva do saldo de renda de propriedade intelectual e variação negativa de balança comercial. Embora apresente essa direção na variação dos saldos, a participação do primeiro no segundo é insignificante. Outra questão ressaltada sobre o país refere-se à sua localização no grupo 1 de países com baixo IP. Apesar de ser altamente integrado à cadeia produtiva americana tem grande parte de sua produção voltada para o mercado doméstico dos EUA, cujo componente (DVADF") não é contabilizado pelo índice de participação, questão já discutida anteriormente. 
Tabela 4 Países com baixa participação nas CGVs-subgrupos

\begin{tabular}{lrr}
\hline Grupo 1 & PIntelectual $(\Delta$ saldo $<0)$ & PIntelectual $(\Delta$ saldo $>$ 0) \\
\hline & África do Sul & Alemanha \\
& Argentina & Suíça \\
BC & Austrália & Suécia \\
$(\Delta$ saldo $>0)$ & Brasil & \\
& China & \\
& Colômbia & \\
& Holanda & \\
\hline & Indonésia & México \\
& Israel & França \\
BC & Rússia & Estados Unidos \\
$(\Delta$ saldo $<0)$ & Hong Kong & Espanha \\
& Costa Rica & Áustria \\
& Filipinas & Reino Unido \\
\hline Indicadores & Itália & \\
\hline 3$) \Delta$ DVA & Portugal & $(<0)$ \\
\hline 4$) \Delta$ DVAs A,B,C & Canadá & $(>0)^{1}$ \\
\hline
\end{tabular}

Fonte: Elaboração própria.

Legenda: $\Delta$ (variação); DVA (VA doméstico nas exportações); DVAs A,B,C (VA de serviços sofisticados nas exportações).

Notas: ${ }^{1}$ México e França: $\triangle D$ VAs A,B,C $(<0)$.

E sobre os serviços intensivos em conhecimento, os países com variação positiva nesse indicador foram geralmente aqueles com variação positiva da renda de uso de propriedade intelectual, evidenciando-se o que já foi comentado antes de relação inversa entre comércio intracadeia e serviços sofisticados como $\mathrm{P} \& \mathrm{D}$, com estes últimos traduzindo-se de alguma forma em pagamento pelo uso de propriedade intelectual.

Grupo 2 Países com grande crescimento de participação nas CGVs e relevância média do comércio intracadeia nas exportações

O grupo 2 refere-se aos países que apresentam maior crescimento da participação nas CGVs no período, embora as exportações no âmbito das ca- 
deias não predominem em suas exportações (IP por volta de $50 \%$ em 2011). Outra característica identificada refere-se à piora dos saldos de renda de pagamento de uso propriedade intelectual, com a maioria apresentando piora também na balança comercial, e alguns poucos, aumento do superávit comercial. O Japão, único país desenvolvido do grupo, apresentou padrão diferente nesse indicador, saldo em propriedade intelectual positivo em contrapartida ao saldo comercial negativo, característico nos países desenvolvidos. Identificou-se também que todos os países do grupo apresentaram redução do VA doméstico e, exceto Chile e Japão, redução em níveis bem altos.

\section{Grupo 3 Países com grande crescimento de participação nas CGVs e com relevância significativa do comércio intracadeia nas exportações}

O grupo 3 refere-se aos países que aumentaram significantemente a participação nas cadeias e com relevância expressiva do comércio intracadeia em suas exportações. A respeito dos saldos de propriedade intelectual e da balança comercial, observa-se predominantemente a piora do primeiro acompanhado quase que majoritariamente por maiores superávits comerciais. Com uma pequena variação, Bulgária apresentando piora também do déficit na BC, e destoando totalmente, Hungria com aumento dos superávits em ambas as contas. Quanto aos demais indicadores, identificou-se redução significativa do VA doméstico nas exportações na maioria desses países. Na Irlanda e na Eslovênia a redução foi inferior, e, como exceção, Cingapura apresentando aumento do DVA. Ressalta-se que esses países apresentaram aumento da participação de serviços intensivos em conhecimento em suas exportações, sendo que em Cingapura e Irlanda, houve aumentos muito significativos.

A técnica de cluster permitiu identificar padrões entre os países referentes à intensidade de participação nas CGVs e o comportamento entre fluxos comerciais e de renda de propriedade intelectual. Embora a metodologia tenha gerado três grupos, os grupos 2 e 3 podem ser agregados representando os países com participação significativa nas CGVs. Com essa agregação, afirma-se que os países que mais ampliaram a importância das cadeias em suas economias foram aqueles que também apresentaram piora nas contas de renda de pagamento pelo uso de propriedade intelectual. 
Identificou-se ainda que os países que mais aumentaram a participação nas cadeias foram os que mais perderam VA doméstico nas exportações. Além disso, a técnica de cluster também mostrou que, entre os países com maior crescimento nas cadeias, poucos o fizeram com aumento da participação de serviços sofisticados.

\section{Conclusão}

Tendo em vista a discussão incipiente na literatura sobre propagação das CGVs e o aprofundamento da institucionalidade internacional de direito de propriedade que influencia o aumento das assimetrias tecnológicas entre os países desenvolvidos e em desenvolvimento devido às suas distintas atuações nas cadeias, buscou-se no presente trabalho fazer um mapeamento da participação dos países nas cadeias simultaneamente ao comportamento de seus fluxos comerciais e de renda de pagamento pelo uso de propriedade intelectual dos países.

Com a análise de clusters, identificou-seque os países com maior participação nas cadeias apresentaram piora nos saldos de renda de pagamento pelo uso de propriedade intelectual, geralmente acompanhada de melhora comercial. Esse resultado, embora sem garantir causalidade entre as variáveis, converge para as discussões sobre propagação das CGVs, fortalecimento da institucionalidade internacional de direito de propriedade e aprofundamento da dependência tecnológica dos países em desenvolvimento em relação aos desenvolvidos, mesmo que a participação nas cadeias venha contribuindo para a melhora comercial. Identificou-se também maior perda de VA doméstico paralelamente à baixa participação de VA em serviços sofisticados entre os países que mais aumentaram a participação nas cadeias. Esses resultados também convergem para a literatura que discute os obstáculos ao upgrading e, com isso, a limitação da participação nas cadeias como mecanismo de aumentar a criação de VA local e seus possíveis transbordamentos para a economia. Mesmo sem causalidade assegurada pela metodologia, o resultado contribui para alimentar a discussão sobre maior dependência tecnológica dos países em desenvolvimento inseridos nesse paradigma produtivo.

Assim, o presente trabalho contribui para elucidar essas discussões iniciais de forma a preencher a lacuna existente de uma análise empírica a 
respeito do assunto. Diante da convergência dos resultados do mapeamento com a discussão teórica realizada até então, emerge-se um novo campo de pesquisa a ser explorado, voltado a aprofundar a análise referente à relação entre participação dos países em desenvolvimento nas CGVs e dependência tecnológica.

\section{Referências}

AGUIAR de MEDEIROS, C. \& TREBAT, N. Inequality and Income Distribution in Global Value Chains. Journal of Economic Issues, 51(2), 401-408, 2017.

BALDWIN, R. Global Supply Chains: Why they Emerged, Why they Matters, and Where They Are Going. Fung Global Institute, Working Paper01, 2012.

BANGA, R. Measuring value in global value chains. Unit of Economic Cooperation and Integration amongst Developing Countries (ECIDC)/UNCTAD Background paper n.RVC-8, 2013.

BANGA, R. Linking into global value chains is not sufficient: Do you export domestic value added contents? Journal of Economic Integration, 267-297, 2014.

CARLOTTO, M. C.; PINTO, J.G. A divisão internacional do trabalho no século XXI: um estudo sobre o peso da propriedade intelectual na relação EUA-América Latina. Carta Internacional, v.10,p.94-113,2015.

CORRÊA, L. M. Trajetórias dos países em desenvolvimento nas cadeias globais de valor: Upgrading, estágio produtivo e mudança estrutural. Tese (Doutorado) - Universidade Federal do Rio de Janeiro, Instituto de Economia, 2016.

CORRÊA, L. M.; PINTO, E. C.; CASTILHO, M. R. Mapeamento dos padrões de atuação dos países nas Cadeias Globais de Valor e os ganhos em termos de mudança estrutural. Econ. Soc., Campinas, v. 28, n. 1, p. 89-122, abr.2019.

DE BACKER, K. \& MIRODOUT,S. Mapping Global Value Chains. OECD Trade Policy Papers, n.159, OECD Publishing. Paris, 2013.

DURAND, C; MILBERG,W. Intellectual Monopoly in Global Value Chains. Working Paper 1.807, New School for Social Research, Department of Economics, 2018.

ERNEST, D.; KIM, L. Global production networks, knowledge diffusion and local capability formation. Research Policy, 34,1.417-1.429, 2002.

HUMPHREY, J.;SCHMITZ, H. How does insertion in global value chains affect upgrading in industrial clusters? Regional Studies, 36:1.017-1.027, 2002.

JOHNSON, R. \& D. WICHERN. Applied Multivariate Statistical Analysis. New Jersey: Editora Pearson, 2007.

KOOPMAN, R.; WANG, Z.; WEI,S. How much of Chinese export is really made in China? Assessing domestic value-added when processing trade is pervasive. Washington: NBER, Mar. 2008.Working Paper, n.14.109. 
KUPFER, D. e HASENCLEVER, L. Economia industrial. Rio de Janeiro: Editora Campus, 2002.

MEMEDOVIC, O. \& IAPADRE, L. Structural Change in the World Economy: Main Features and Change, UNIDO, Research and Statistics Branch, Working Paper n.24, 2009.

MILBERG, W. \& WINKLER, D. Outsourcing Economics: Global value chains in capitalist development. New York: Cambridge University Press, 2013.

MIRANDA, P.C. A internacionalização das atividades tecnológicas e inserção dos países em desenvolvimento: uma análise baseada em dados de patentes.Tese (Doutorado)- UNICAMP, 2014.

OECD-WTO. Trade in Value-Added: Concepts, Methodologies and Challenges, Joint OECD_WTO Note, March 15, 2012.

PAGANO'S, U. The Crisis of Intellectual Monopoly Capitalism. Cambridge Journal of Economics, 38(6),1.409-1.429, 2014.

PINTO, E.C.; FIANE, R. e CORRÊA, L.M. Dimensões da abordagem da Cadeia Global de Valor: upgrading, governança, políticas governamentais e propriedade intelectual. Brasília: IPEA. Texto para discussão, n.2.155, 2015.

SARTI, F. e HIRATUKA, C. (Coord.). Perspectivas do investimento na indústria. Rio de Janeiro: Synergia: UFRJ, Instituto de Economia; Campinas: UNICAMP, Instituto de Economia. (Projeto PIB), 2010.

SMICHOWSKI, B.;DURAND, C.; KNAUSS, S. Participation in global value chains and varieties of development patterns, 2018. <hal-01817426>

STURGEON, T. \& GEREFFI, G. Measuring Success in the Global Economy: International Trade, Industrial Upgrading, and Business Function Outsourcing in Global Value Chains. Transitional Corporations, v.18, n.2, p.1-36, 2009.

STURGEON, T. \& MEMEDOVIC, O. Mapping Global Value Chains: Intermediate Goods Trade and Structural Change in the World Economy. Development Policy and Strategic Research Branch. Working Paper 05. Vienna: UNIDO, 2010.

TAGLIONI, D.; WINKLER, D. Making Global Value Chains Work for Development. Washington, D.C.: The World Bank, 2016.

UNCTAD -WIR13. World Investment Report 2013: Global Value Chains: Investment and Trade for development. New York; Geneva: United Nations, 2013.

UNCTAD-WIR18. World Investment Report 2018: Investments and New Industrial Policies. New York; Geneva: United Nations, 2018.

UNIDO. Industrial Development Report 2013. Sustaining Employment Growth: The Role of Manufacturing and Structural Change. Viena, 2013.

\section{Sobre os autores}

Ludmila Macedo Corrêa - macedo.ludmila@gmail.com

Departamento de Ciências Econômicas e Exatas, Universidade Federal Rural do Rio de Janeiro, Três Rios, RJ, Brasil. ORCID: https://orcid.org/0000-0002-0739-8096.

Eduardo Costa Pinto-eduardo.pinto@ie.ufri.br

Instituto de Economia, Universidade Federal do Rio de Janeiro, Rio de Janeiro, RJ, Brasil.

ORCID: https://orcid.org/0000-0003-0617-1073. 
Marta dos Reis Castilho-castilho@ie.ufri.br

Instituto de Economia, Universidade Federal do Rio de Janeiro, Rio de Janeiro, RJ, Brasil. ORCID: https://orcid.org/0000-0002-1483-4597.

\section{Sobre o artigo}

Recebido em 10 de setembro de 2018. Aprovado em 25 de setembro de 2019. 


\section{APÊNDICE}

Tabela A1 Matriz de correlação

\begin{tabular}{|c|c|c|c|c|c|c|c|}
\hline \multicolumn{8}{|c|}{ Correlations } \\
\hline & & & \multicolumn{2}{|c|}{ Prop. Intelectual } & \multicolumn{2}{|c|}{ Balança Comercia } \\
\hline \multirow{3}{*}{\multicolumn{2}{|c|}{ Prop. Intelectual }} & \multirow{2}{*}{\multicolumn{2}{|c|}{$\begin{array}{l}\text { Pearson Correlation } \\
\text { Sig. (2-tailed) }\end{array}$}} & \multirow{2}{*}{\multicolumn{2}{|c|}{1}} & \multicolumn{2}{|r|}{,$- 808^{* *}$} \\
\hline & & & & & & \multicolumn{2}{|r|}{,000 } \\
\hline & & \multicolumn{2}{|l|}{$\mathrm{N}$} & \multicolumn{2}{|r|}{41} & \multirow{2}{*}{\multicolumn{2}{|c|}{$\begin{array}{r}41 \\
1\end{array}$}} \\
\hline \multirow{3}{*}{\multicolumn{2}{|c|}{ Balança Comercial }} & \multicolumn{2}{|c|}{ Pearson Correlation } & \multicolumn{2}{|r|}{,$- 808^{* *}$} & & \\
\hline & & \multicolumn{2}{|c|}{ Sig. (2-tailed) } & \multicolumn{2}{|r|}{, 000} & \multirow{2}{*}{\multicolumn{2}{|c|}{41}} \\
\hline & & \multicolumn{2}{|l|}{$\mathrm{N}$} & \multicolumn{2}{|r|}{41} & & \\
\hline \multicolumn{8}{|c|}{ Correlations: todos os indicadores } \\
\hline & & & $\begin{array}{r}\text { IP } \\
2011\end{array}$ & $\Delta \mathbf{I P}$ & $\triangle \mathrm{DVA}$ & $\begin{array}{r}\Delta \text { VAX } \\
\text { serv }\end{array}$ & $\begin{array}{r}\text { P. } \\
\text { Intel_BC }\end{array}$ \\
\hline \multirow{3}{*}{ IP2011 } & \multicolumn{2}{|c|}{ Pearson Correlation } & 1 &, $333^{*}$ &,$- 382^{*}$ &,- 072 &,- 099 \\
\hline & \multicolumn{2}{|c|}{ Sig. (2-tailed) } & & 027 & 010 & 642 &, 533 \\
\hline & \multicolumn{2}{|l|}{$\mathrm{N}$} & 41 & 41 & 41 & 41 & 41 \\
\hline \multirow{3}{*}{$\Delta \mathrm{IP}$} & \multicolumn{2}{|c|}{ Pearson Correlation } &, $333^{*}$ & 1 &,$- 820^{* *}$ &,$- 440^{* *}$ & 056 \\
\hline & \multicolumn{2}{|c|}{ Sig. (2-tailed) } & 027 & & ,000 & ,003 & ,727 \\
\hline & \multicolumn{2}{|l|}{$\mathrm{N}$} & 41 & 41 & 41 & 41 & 41 \\
\hline \multirow{3}{*}{$\triangle \mathrm{DVA}$} & \multicolumn{2}{|c|}{ Pearson Correlation } &,$- 382^{*}$ &,$- 820^{* *}$ & 1 & ,283 &,- 205 \\
\hline & \multicolumn{2}{|c|}{ Sig. (2-tailed) } & 010 &, 000 & & ,063 & 192 \\
\hline & \multicolumn{2}{|l|}{$\mathrm{N}$} & 41 & 41 & 41 & 41 & 41 \\
\hline & Pearson & rrelation &,- 072 &,$- 440^{* *}$ & ,283 & 1 & ,112 \\
\hline$\triangle$ VAXserv & Sig. $(2-t$ & & ,642 & ,003 & ,063 & & ,481 \\
\hline & $\mathrm{N}$ & & 41 & 41 & 41 & 41 & 41 \\
\hline & Pearson & rrelation &,- 099 & ,056 &,- 205 & 112 & 1 \\
\hline Prop. & Sig. (2-t & &, 533 & ,727 & ,192 & ,481 & \\
\hline & $\mathrm{N}$ & & 41 & 41 & 41 & 41 & 41 \\
\hline
\end{tabular}

Fonte: Matriz de correlação obtida através do software estatístico SPSS.

** Correlation is significant at the 0.01 level (2-tailed). 
Tabela A2 Todos os indicadores agrupados

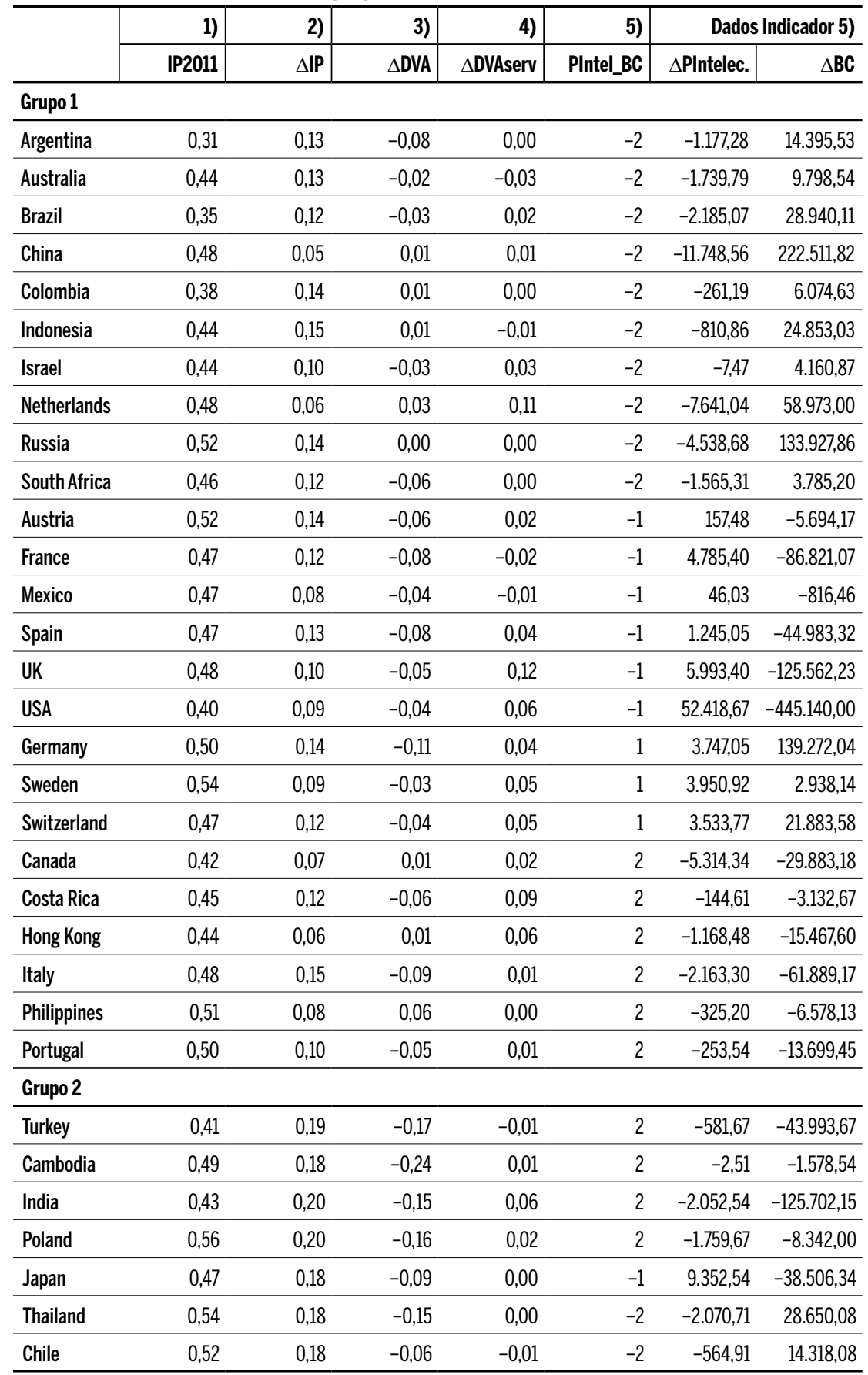


Tabela A2 (continuação)

\begin{tabular}{|c|c|c|c|c|c|c|c|}
\hline & \multirow{2}{*}{\begin{tabular}{|r|}
$1)$ \\
IP2011
\end{tabular}} & \multirow{2}{*}{$\begin{array}{r}\text { 2) } \\
\Delta \mathrm{IP}\end{array}$} & \multirow{2}{*}{\begin{tabular}{r|}
$3)$ \\
$\Delta$ DVA \\
\end{tabular}} & \multirow{2}{*}{$\begin{array}{r}\text { 4) } \\
\Delta \text { DVAserv }\end{array}$} & \multirow{2}{*}{$\begin{array}{r}\text { 5) } \\
\text { PIntel_BC }\end{array}$} & \multicolumn{2}{|c|}{ Dados Indicador 5) } \\
\hline & & & & & & $\Delta$ PIntelec. & $\triangle \mathrm{BC}$ \\
\hline \multicolumn{8}{|l|}{ Grupo 3} \\
\hline Hungary & 0,65 & 0,22 & $-0,19$ & $-0,01$ & 1 & 111,73 & $6.161,93$ \\
\hline Slovak & 0,67 & 0,17 & $-0,15$ & $-0,02$ & -2 & $-62,73$ & $1.596,82$ \\
\hline Czech Rep. & 0,65 & 0,17 & $-0,15$ & $-0,02$ & -2 & $-705,14$ & $8.937,69$ \\
\hline Korea & 0,62 & 0,23 & $-0,19$ & 0,02 & -2 & $-2.104,17$ & $51.417,77$ \\
\hline Malaysia & 0,60 & 0,14 & $-0,10$ & $-0,01$ & -2 & $-1.189,98$ & $39.272,71$ \\
\hline Slovenia & 0,59 & 0,12 & $-0,04$ & 0,02 & -2 & $-273,84$ & 159,60 \\
\hline Bulgaria & 0,57 & 0,12 & $-0,10$ & 0,02 & 2 & $-98,90$ & $-4.962,32$ \\
\hline Ireland & 0,59 & 0,08 & $-0,05$ & 0,14 & -2 & $-13.764,39$ & $18.338,88$ \\
\hline Singapore & 0,62 & 0,07 & 0,01 & 0,06 & -2 & $-13.514,24$ & $49.887,07$ \\
\hline
\end{tabular}

Fonte: Elaboração própria. 